\title{
Mass spectral chemical fingerprints reveal the molecular dependence of exhaust particulate matters on engine speeds
}

\author{
Yi $\mathrm{Li}^{1}$, Hua Zhang ${ }^{1}$, Zongshan Zhao ${ }^{2}$, Yong Tian ${ }^{2}{ }^{*}$, Kun Liu $^{1}$, Feifan Jie ${ }^{1}$, \\ Liang $\mathrm{Zhu}^{1}$, Huanwen Chen ${ }^{1, *}$ \\ 1. Jiangxi Key Laboratory for Mass Spectrometry and Instrumentation, East China University of Technology, Nanchang 330013, China \\ 2. CAS Key Laboratory of Biobased Materials, Qingdao Institute of Bioenergy and Bioprocess Technology, Chinese Academy of Sciences, \\ Qingdao 266101, China
}

\section{A R T I C L E I N F O}

\section{Article history:}

Received 27 May 2017

Revised 9 September 2017

Accepted 13 September 2017

Available online $\mathrm{xxxx}$

Keywords:

Exhaust particulate matters

Engine speeds

Mass spectral

Chemical fingerprints

\begin{abstract}
A B S T R A C T
Particulate matters (PMs) emitted by automobile exhaust contribute to a significant fraction of the global PMs. Extractive atmospheric pressure chemical ionization mass spectrometry (EAPCI-MS) was developed to explore the molecular dependence of PMs collected from exhaust gases produced at different vehicle engine speeds. The mass spectral fingerprints of the organic compounds embedded in differentially sized PMs (e.g., $0.22-0.45,0.45-1.00,1.00-2.00,2.00-3.00,3.00-5.00$, and 5.00-10.00 $\mu \mathrm{m}$ ) generated at different engine speeds (e.g., 1000, 1500, 2000, 2500, and $3000 \mathrm{r} / \mathrm{min}$ ) were chemically profiled in the mass range of mass to charge ratio $(\mathrm{m} / \mathrm{z})$ 50-800. Organic compounds, including alcohols, aldehydes, and esters, were detected in all the PMs tested, with varied concentration levels for each individual PM sample. At relatively low engine speeds $(\leq 1500 \mathrm{r} / \mathrm{min}$ ), the total amount of organic species embedded in PMs of $0.22-1.00 \mu \mathrm{m}$ was greater than in PMs of other sizes, while more organic species were found in PMs of $5.00-10.00 \mu \mathrm{m}$ at high engine speeds $(\geq 3000 \mathrm{r} / \mathrm{min})$, indicating that the organic compounds distributed in different sizes of PMs strongly correlated with the engine speed. The experimental data showed that the EAPCI-MS technique enables molecular characterization of PMs in exhaust, revealing the chemical dependence of PMs on the engine speeds (i.e., the combustion conditions) of automobiles.
\end{abstract}

(C) 2017 The Research Center for Eco-Environmental Sciences, Chinese Academy of Sciences. Published by Elsevier B.V.

\section{Introduction}

Atmospheric particulate matters (PMs), also known as particulate matters or atmospheric aerosol, are considered to be one of the most serious pollutants and cause serious health issues, such as cardiovascular and respiratory diseases and even mortality (Yuan et al., 2012; Chen et al., 2016a; Tao et al., 2014; Nguyen et al., 2015; Li et al., 2016; Qu et al., 2016; Pui et al., 2014; Maria et al., 2002). With the rapidly increasing amount of vehicles in use, automobile exhaust gases are becoming the main sources of PMs in urban areas (Goel and Guttikunda, 2015; Calvo et al., 2013; Karar and Gupta, 2007; Liu et al., 2016a; Kleeman et al., 2000; Police et al., 2016). In particular, fine PMs (particle diameter $\leq 2.5 \mu \mathrm{m}$ ) arouse greater worldwide concerns than coarse PMs (diameter of particle $\leq 10 \mu \mathrm{m}$ ) because fine PMs are able to penetrate lung cells, giving increased toxicity, and scatter light efficiently, leading to extensive visibility reduction (Choi et al., 2012; Chen et al., 2016b, 2016c; Liu et al., 2016b). The physical properties, visibility, health effects, mitigation, and transformation of

\footnotetext{
* Corresponding authors. E-mail: tianyong@qibebt.ac.cn (Yong Tian), chw8868@gmail.com (Huanwen Chen).
} 
$\mathbf{a}$

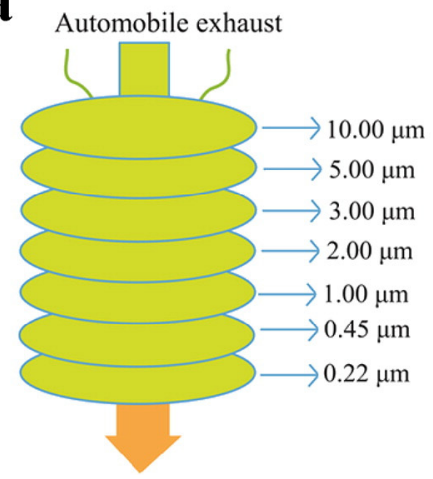

b

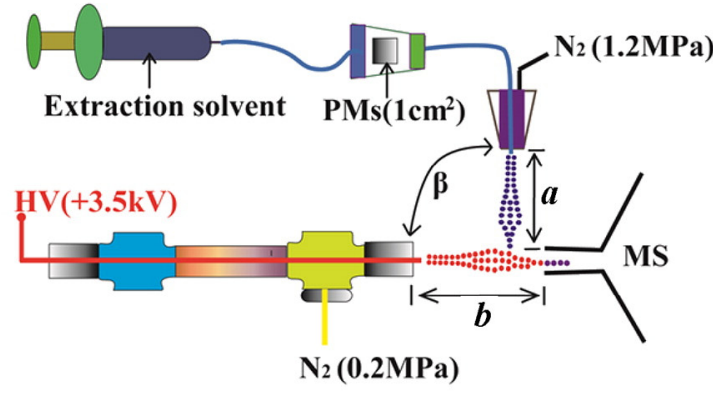

$a=1.0 \mathrm{~cm} \quad b=0.5 \mathrm{~cm} \quad$ Angle $\beta=90^{\circ}$

Fig. 1 - Schematic diagram of the collection for different size particulate matters (PMs) using a series of membranes with different apertures (a) and extractive atmospheric pressure chemical ionization mass spectrometry (EAPCI-MS) for the analysis of PM samples (b). Note: $a$ is the distance between MS inlet and sample sprayer, $b$ is the distance between MS inlet and the atmospheric pressure chemical ionization sprayer, angle $\beta$ is the angle between two sprayers.

atmospheric PMs (Hoffmann et al., 2011; Gerald et al., 2010; Poschl and Shiraiwa, 2015; Zhou et al., 2016a; Pope and Dockery, 2006) have been extensively studied; however, the potential correlations between the molecular compositions of exhaust PMs and different vehicle engine speeds remain unknown. Consequently, exploring the dependence of the chemical compositions of PMs on the engine speeds (i.e., the combustion conditions) of automobiles requires novel analytical methods for the molecular characterization of PMs in exhaust.

Mass spectrometry is preferably employed for the characterization of organic compounds in atmospheric aerosol due to its high sensitivity and selectivity (Ruger et al., 2015; Parshintsev and Hyötyläinen, 2015; Roach et al., 2010; Bruggemann et al., 2015; Romonosky et al., 2015). A wide range of organic and inorganic chemical species in atmospheric aerosol particles have been detected, such as alkanes, olefins, ketones, aldehydes, carboxylic acid, monoterpenes, sugars, heavy metals, and polycyclic aromatic hydrocarbons (Yadav et al., 2013; Tu et al., 2016; Kundu et al., 2012; Kaivosoja et al., 2013), depending on the sources of the PMs. Among the mass spectrometry methods available, the aerosol mass spectrometer (AMS) is widely used today (Peck et al., 2016; Spracklen et al., 2011; Zhou et al., 2016b; Daellenbach et al., 2016). Second organic aerosol (SOA) and semi-volatile organic compounds (SVOCs) (Kinsey et al., 2011; Kuwayama et al., 2015) in exhaust PMs have been traditionally analyzed by mass spectrometry. However, abundant fragment ions are unavoidably obtained due to the excess internal energy added by the electron impact (EI, $70 \mathrm{eV}$ ) ionization source, resulting in difficulties in data interpretation. Therefore, a soft ionization method would favor such applications by enabling the molecular information to be obtained directly. Recently, Dunmore and colleagues demonstrated that diesel-related hydrocarbons comprise more than $50 \%$ of atmospheric hydrocarbon (Dunmore et al., 2015). Ensberg et al. (2014) studied emission factor ratios and the impact of automobile emissions on SOA formation. Ruger et al. (2015) conducted research on ship diesel primary PMs by means of ultra-high-resolution mass spectrometry (MS) combined with laser desorption ionization and Sippula et al. (2014) studied the chemical composition of PM emissions from a medium-speed four-stroke marine engine operated on both heavy oil and distillate fuel. However, the potential chemical component dependence of the PMs on engine combustion conditions has been rarely reported in the literature.

As one of the novel ambient ionization techniques, extractive atmospheric pressure chemical ionization mass spectrometry (EAPCI-MS) combines the advantages of atmospheric pressure chemical ionization (APCI) and extractive electrospray ionization (EESI) (Hu et al., 2008). In its ionization process, neutral liquid samples are continuously introduced to spray and collide with the plasma generated by a corona discharge. During the collision, the analytes are effectively ionized by the extractive
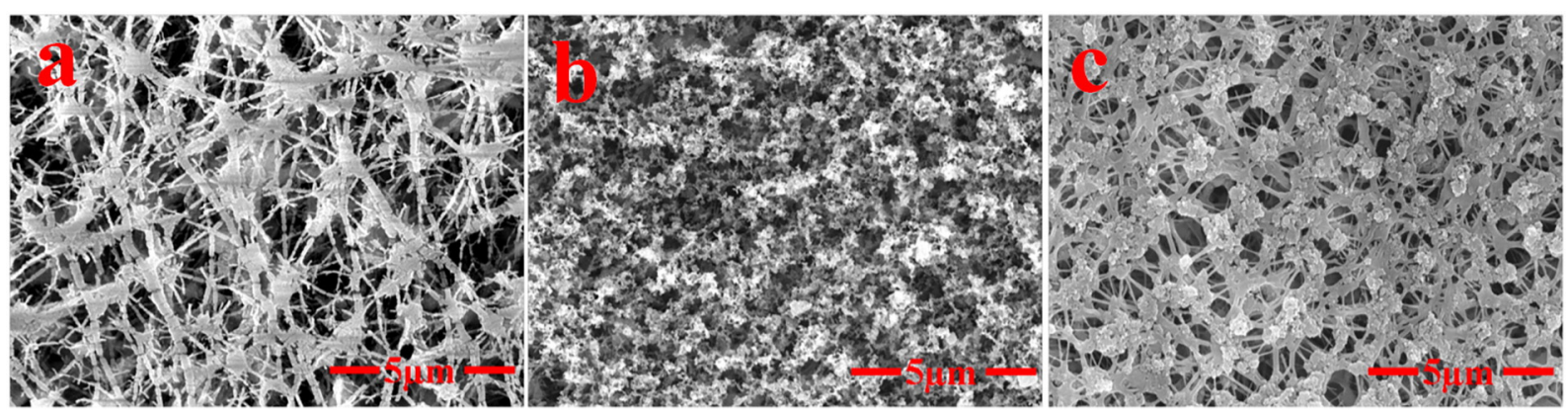

Fig. 2 - (a) Scanning electron microscopy (SEM) images of blank polytetrafluoroethylene (PTFE) membrane with aperture size of $2.0 \mu \mathrm{m}$, (b) PMs in the size range of 2.00-3.00 $\mu \mathrm{m}$ with a membrane aperture size of $2.0 \mu \mathrm{m}$ and (c) 5.00-10.00 $\mu \mathrm{m}$ with a membrane aperture size of $5.0 \mu \mathrm{m}$ under an engine speed of $1000 \mathrm{r} / \mathrm{min}$. 
and charge transfer process under ambient conditions. The current work aims to establish a novel analytical technique based on EAPCI-MS to facilitate profiling the chemical fingerprints of PMs, which were collected from the exhaust gas flow generated under different engine speeds of 1000, 1500, 2000, 2500, and $3000 \mathrm{r} / \mathrm{min}$ with differentially centered sizes of $0.22-0.45,0.45-1.00,1.00-2.00,2.00-3.00,3.00-5.00$, and 5.00-10.00 $\mu \mathrm{m}$. The experimental results show a strong chemical dependence of the PMs on the engine combustion conditions (i.e., the engine speeds, combustion efficiency), which was clearly revealed by the EAPCI-MS method proposed in this work.

\section{Materials and methods}

\subsection{Material and chemicals}

Polytetrafluoroethylene (PTFE) filter membranes with a 90-mm diameter and different apertures $(0.22,0.45,1.00,2.00,3.00,5.00$, and $10.00 \mu \mathrm{m})$ were purchased from Munktell Filter AB Company (Falun, Sweden). High performance liquid chromatography (HPLC)-grade methanol and acetic acid were purchased from Return On Equity (ROE) Scientific Inc. (Newark, USA). Analytical reagent grade glycerin and phthalate butyl ester were purchased from Sinopharm Chemical Reagent Co. Ltd. (Shanghai, China). Unless otherwise stated, all chemicals were directly used without any pretreatment.

\subsection{Particulate matter sampling procedure}

The schematic diagram of the collection process for automobile exhaust PMs samples of different size ranges is shown in Fig. 1a. The PM samples were directly collected from the emission of a vehicle (Shanghai Volkswagen Lavida 1.6 L, EA211 engine, China) with all sizes of PTFE filter membranes (0.22, 0.45, 1.00, $2.00,3.00,5.00$, and $10.00 \mu \mathrm{m}$ ) without any treatment. For the simultaneous collection of different size PMs, filter membranes with different apertures were overlapped together in the order of $0.22,0.45,1.00,2.00,3.00,5.00$, and $10.00 \mu \mathrm{m}$. The set of filter membranes was locked in a tube that was connected to the engine's tailpipe, and a pump was used to extract the exhaust emissions. To collect PM samples under different engine combustion conditions, different engine speeds, including 1000, 1500, 2000, 2500, and $3000 \mathrm{r} / \mathrm{min}$, were applied to the vehicle. The collected PM samples on the PTFE filter membranes were further imaged with a scanning electron microscope (Nova Nano 450, FEI, USA).

\subsection{EAPCI-MS analysis of PM samples}

The EAPCI-MS analytical process for the PM samples is shown in Fig. 1b. For each analysis, the filter membrane with PM was cut into pieces $\left(1.0 \mathrm{~cm}^{2}\right)$ for the EAPCI-MS sample, followed by placing it in the sample loading tube. Next, the methanol/water/acetic acid (v/v/v 50: 50: 3) extraction solvent was pumped at a flow rate of $5 \mu \mathrm{L} / \mathrm{min}$ into the sample tube for the chemical extraction of the PMs on the filter membrane, followed by spraying to the APCI nebulizer connected to a linear trap quadrupole (LTQ) mass spectrometer (LTQ XL, Thermo Scientific, USA). Mass spectra were collected in the mass range of mass to charge ratio
Table 1 - Possible chemical components of particulate matters (PMs) emitted from automobile exhaust analyzed by extractive atmospheric pressure chemical ionization mass spectrometry (EAPCI-MS) and Thermo Xcalibur software.

\begin{tabular}{ccc}
$\begin{array}{c}\text { Mass to charge } \\
\text { ratio }(\mathrm{m} / \mathrm{z})\end{array}$ & $\begin{array}{c}\text { Possible } \\
\text { components }\end{array}$ & $\begin{array}{c}\text { Calculated } \\
\text { compounds }\end{array}$ \\
\hline
\end{tabular}

\begin{tabular}{|c|c|c|}
\hline 75 & $\mathrm{C}_{4} \mathrm{H}_{13} \mathrm{~N}, \mathrm{C}_{4} \mathrm{H}_{11} \mathrm{O}$ & \\
\hline 78 & $\mathrm{C}_{6} \mathrm{H}_{6}, \mathrm{C}_{3} \mathrm{H}_{10} \mathrm{~S}$ & \\
\hline 83 & $\mathrm{C}_{6} \mathrm{H}_{11}, \mathrm{C}_{5} \mathrm{H}_{9} \mathrm{~N}$ & 2-Cyclopentenone \\
\hline 93 & $\mathrm{C}_{3} \mathrm{H}_{8} \mathrm{O}_{3}$ & Glycerol \\
\hline 97 & $\mathrm{C}_{5} \mathrm{H}_{5} \mathrm{~S}, \mathrm{C}_{4} \mathrm{H}_{3} \mathrm{O}_{2} \mathrm{~N}$ & \\
\hline 121 & $\mathrm{C}_{6} \mathrm{H}_{5} \mathrm{ON}_{2}, \mathrm{C}_{6} \mathrm{H}_{3} \mathrm{NS}$ & \\
\hline 125 & $\mathrm{C}_{5} \mathrm{H}_{3} \mathrm{ONS}, \mathrm{C}_{3} \mathrm{H}_{9} \mathrm{OS}_{2}$ & \\
\hline 128 & $\mathrm{C}_{8} \mathrm{H}_{18} \mathrm{~N}, \mathrm{C}_{10} \mathrm{H}_{8}$ & Naphthalene \\
\hline 132 & $\mathrm{C}_{6} \mathrm{H}_{14} \mathrm{NS}, \mathrm{C}_{5} \mathrm{H}_{10} \mathrm{ONS}$ & \\
\hline 143 & $\mathrm{C}_{8} \mathrm{H}_{12} \mathrm{O}$ & $\begin{array}{l}\text { 4-Hydroxy-5- } \\
\text { ethylhexenal }\end{array}$ \\
\hline 149 & $\mathrm{C}_{5} \mathrm{H}_{11} \mathrm{O}_{2} \mathrm{NS}, \mathrm{C}_{9} \mathrm{H}_{9} \mathrm{~S}$ & \\
\hline 153 & $\mathrm{C}_{9} \mathrm{H}_{13} \mathrm{O}_{2}, \mathrm{C}_{9} \mathrm{H}_{13} \mathrm{~S}$ & \\
\hline 163 & $\mathrm{C}_{7} \mathrm{H}_{5} \mathrm{~N}_{3} \mathrm{~S}, \mathrm{C}_{9} \mathrm{H}_{9} \mathrm{O}_{2} \mathrm{~N}$ & \\
\hline 181 & $\mathrm{C}_{9} \mathrm{H}_{13} \mathrm{O}_{4} \mathrm{~N}_{2}, \mathrm{C}_{9} \mathrm{H}_{9} \mathrm{NS}$ & \\
\hline 195 & $\mathrm{C}_{14} \mathrm{H}_{11} \mathrm{O}, \mathrm{C}_{6} \mathrm{H}_{15} \mathrm{O}_{3} \mathrm{~N}_{2} \mathrm{~S}$ & \\
\hline 225 & $\mathrm{C}_{7} \mathrm{H}_{19} \mathrm{O}_{3} \mathrm{~N}_{3} \mathrm{~S}, \mathrm{C}_{15} \mathrm{H}_{15} \mathrm{ON}$ & \\
\hline 256 & $\mathrm{C}_{17} \mathrm{H}_{38} \mathrm{~N}, \mathrm{C}_{16} \mathrm{H}_{36} \mathrm{~N}_{2}$ & \\
\hline 274 & $\mathrm{C}_{15} \mathrm{H}_{38} \mathrm{~N}_{4}, \mathrm{C}_{16} \mathrm{H}_{36} \mathrm{NS}$ & \\
\hline 279 & $\mathrm{C}_{16} \mathrm{H}_{22} \mathrm{O}_{4}$ & Diisobutyl phthalate \\
\hline 294 & $\mathrm{C}_{13} \mathrm{H}_{12} \mathrm{ONS}_{3}, \mathrm{C}_{5} \mathrm{H}_{16} \mathrm{O}_{3} \mathrm{~N}_{3} \mathrm{~S}_{4}$ & \\
\hline 299 & $\mathrm{C}_{5} \mathrm{H}_{11} \mathrm{O}_{9} \mathrm{~N}_{6}, \mathrm{C}_{7} \mathrm{H}_{13} \mathrm{O}_{10} \mathrm{~N}_{3}$ & \\
\hline 338 & $\mathrm{C}_{23} \mathrm{H}_{48} \mathrm{~N}, \mathrm{C}_{24} \mathrm{H}_{50}$ & \\
\hline 575 & $\mathrm{C}_{26} \mathrm{H}_{59} \mathrm{O}_{4} \mathrm{~N}_{10}, \mathrm{C}_{14} \mathrm{H}_{7} \mathrm{O}_{5} \mathrm{~S}_{10}$ & \\
\hline 590 & $\mathrm{C}_{23} \mathrm{H}_{54} \mathrm{O}_{9} \mathrm{~N}_{6} \mathrm{~S}, \mathrm{C}_{30} \mathrm{H}_{52} \mathrm{ON}_{7} \mathrm{~S}_{2}$ & \\
\hline 389 & $\mathrm{HO}\left(\mathrm{CH}_{2} \mathrm{CH}_{2} \mathrm{O}\right)_{n} \mathrm{H}$ & Polyethylene glycol \\
\hline \multicolumn{3}{|l|}{433} \\
\hline \multicolumn{3}{|l|}{477} \\
\hline \multicolumn{3}{|l|}{521} \\
\hline \multicolumn{3}{|l|}{565} \\
\hline \multicolumn{3}{|l|}{609} \\
\hline \multicolumn{3}{|l|}{653} \\
\hline 669 & & \\
\hline
\end{tabular}

C, H, O, N and S were selected to calculate the assignments of mass peaks observed in the mass spectra.

$(\mathrm{m} / \mathrm{z})$ 50-800 in positive ion detection mode. The experimental parameters followed our previous study (Hu et al., 2008). Briefly, the ionization voltage was set at $+3.5 \mathrm{kV}$, and the temperature of the heated LTQ capillary was maintained at $150^{\circ} \mathrm{C}$. The pressure of the nitrogen sheath gas was $1.2 \mathrm{MPa}$. Collision induced dissociation (CID) experiments were carried out for tandem mass spectrometry (MS/MS) analysis with a window width of $1.5 \mathrm{Da}$ and a normalized collision energy (NCE) of $15 \%-40 \%$. Other parameters were set to the default values of the LTQ instrument.

\section{Results and discussion}

\subsection{Characterization of PM samples by scanning electron microscopy}

The surface morphology of the PTFE filter membrane was comparatively studied by scanning electron microscopy (SEM) before and after sampling. Fig. 2 illustrates the SEM images 

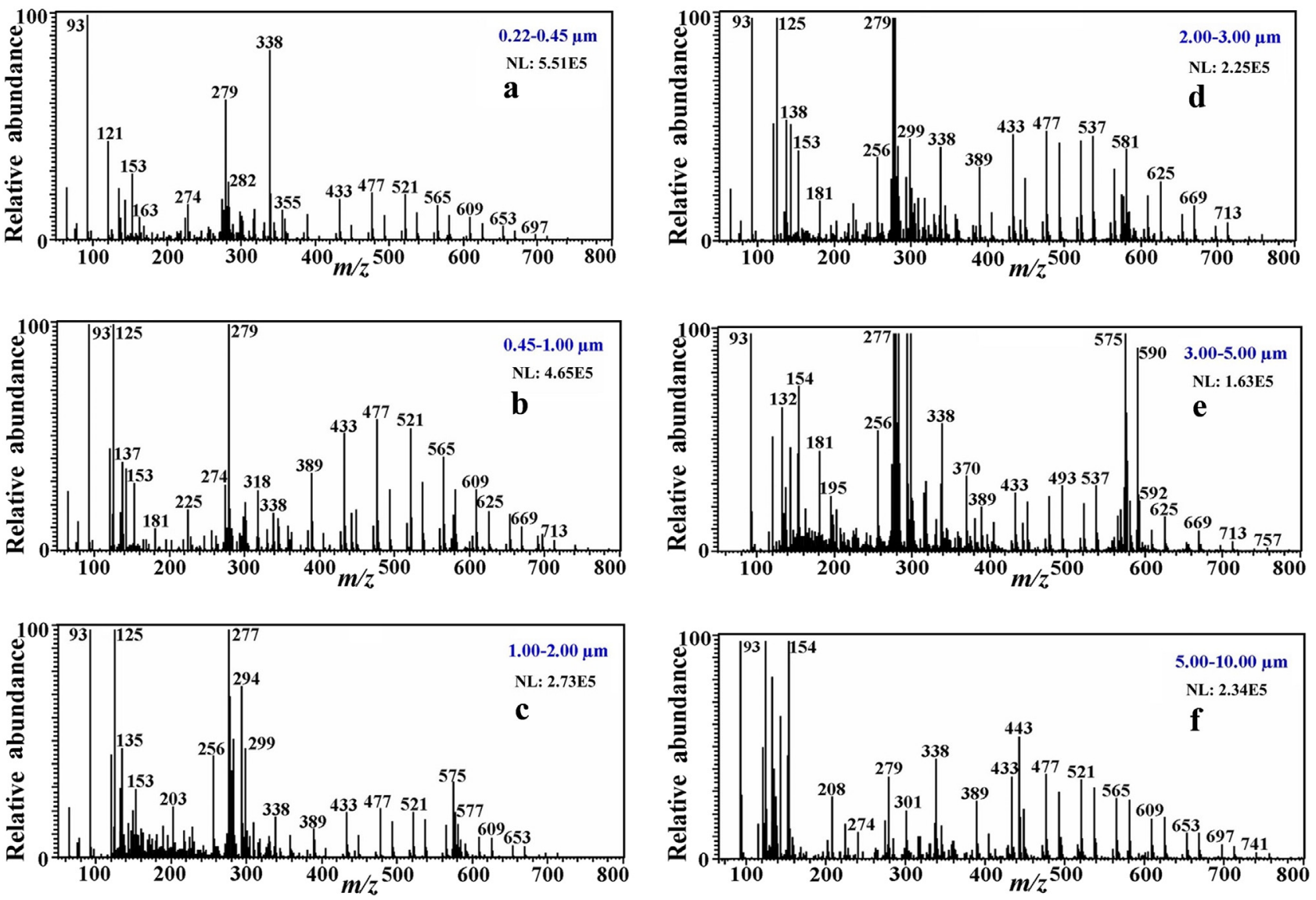

Fig. 3 - EAPCI-MS spectra of automobile exhaust PMs of different particle sizes with constant engine speed at $1000 \mathrm{r} / \mathrm{min}$. PMs with particle sizes (a) 0.22-0.45, (b) 0.45-1.0, (c) 1.0-2.0, (d) 1.0-2.0, (e) 3.0-5.0 and (f) 5.0-10.0 $\mu \mathrm{m}$. Note: the relative abundance of $\mathrm{m} / \mathrm{z}$ 120-800 was magnified 30 times. $\mathrm{m} / \mathrm{z}$ : mass-to charge ratio; NL: normalize level.

of a blank PTFE filter membrane and a PM-loaded PTFE filter membrane. In comparison with the blank PTFE filter membrane (Fig. 2a), PMs of $2.00-3.00 \mu \mathrm{m}$ (Fig. 2b) and 5.00-10.00 $\mu \mathrm{m}$ (Fig. 2c) were loaded on the surface of the blank PTFE membrane. Thus, the successful sample collection was confirmed by the SEM images, showing that the PM-loaded filter membranes could be used for subsequent EAPCI-MS analysis.

\subsection{EAPCI-MS analysis of differentially sized PMs}

Differentially sized PM samples collected from automobile emissions generated under different engine speeds were successfully analyzed by EAPCI-MS in positive ion detection mode. The possible assignments of the mass peaks are summarized in Table 1. As shown in Fig. 3, dominant mass peaks at $m / z$ $83,93,121,153,181,251,279,299,318,338,355$, etc. were detected in all sizes of PMs generated at an engine speed of $1000 \mathrm{r} / \mathrm{min}$. The signals of interest were tentatively identified using CID experiments, with the authentic compounds as reference. Organic compounds, including ketone (cyclopent-2-enone, $\mathrm{m} / \mathrm{z}$ 83), alcohols (glycerol, $m / z$ 93, 4-hydroxy-oct-5-enal, $m / z$ 143), ester (diisobutyl phthalate, $m / z$ 279), etc. were detected in the PM samples. A small mass peak of polycyclic aromatic hydrocarbons
(PAHs) was also detected, e.g. $\mathrm{m} / \mathrm{z}$ at 128 might be attributed to naphthalene in Fig. 3. These results revealed that the PAHs were not the major component in these PMs. More interestingly, the peaks in the relatively high mass range, such as $m / z 389,433$, $477,521,565,609,653$, and 669 , were ascribed to the formation of polyethylene glycol in the process of gasoline combustion. The characteristic mass shift of $44 \mathrm{Da}$ in the mass spectral fingerprints is consistent with the mass spectrum recorded by EAPCI-MS using standard polyethylene glycol. According to the literature (Kong et al., 2008; Mortaheb et al., 2012) polyethylene glycol is used as a templating agent of a gasoline catalyst for increasing fuel efficiency and reduction of environmental pollution. However, no such signal was detected from the raw fuel of the vehicle, indicating that the polyethylene glycol detected by EAPCI-MS from the PMs was not artificially spiked. Possibly, polyethylene glycol was formed via polymerization of the glycol monomer, which might be generated from the residue of alkanes in the gasoline fuel during the combustion as a result of the unique conditions created in the engine. In addition, the organic compounds found in differentially sized PM samples generated under the same combustion conditions presented varying intensity levels. For example, more organic compounds were detected from the PMs of small sizes (e.g., 0.22-0.45 $\mu \mathrm{m}$ ) rather than the large sizes (e.g., 3.00-5.00 $\mu \mathrm{m}, 5.00-10.00 \mu \mathrm{m}$ ) 

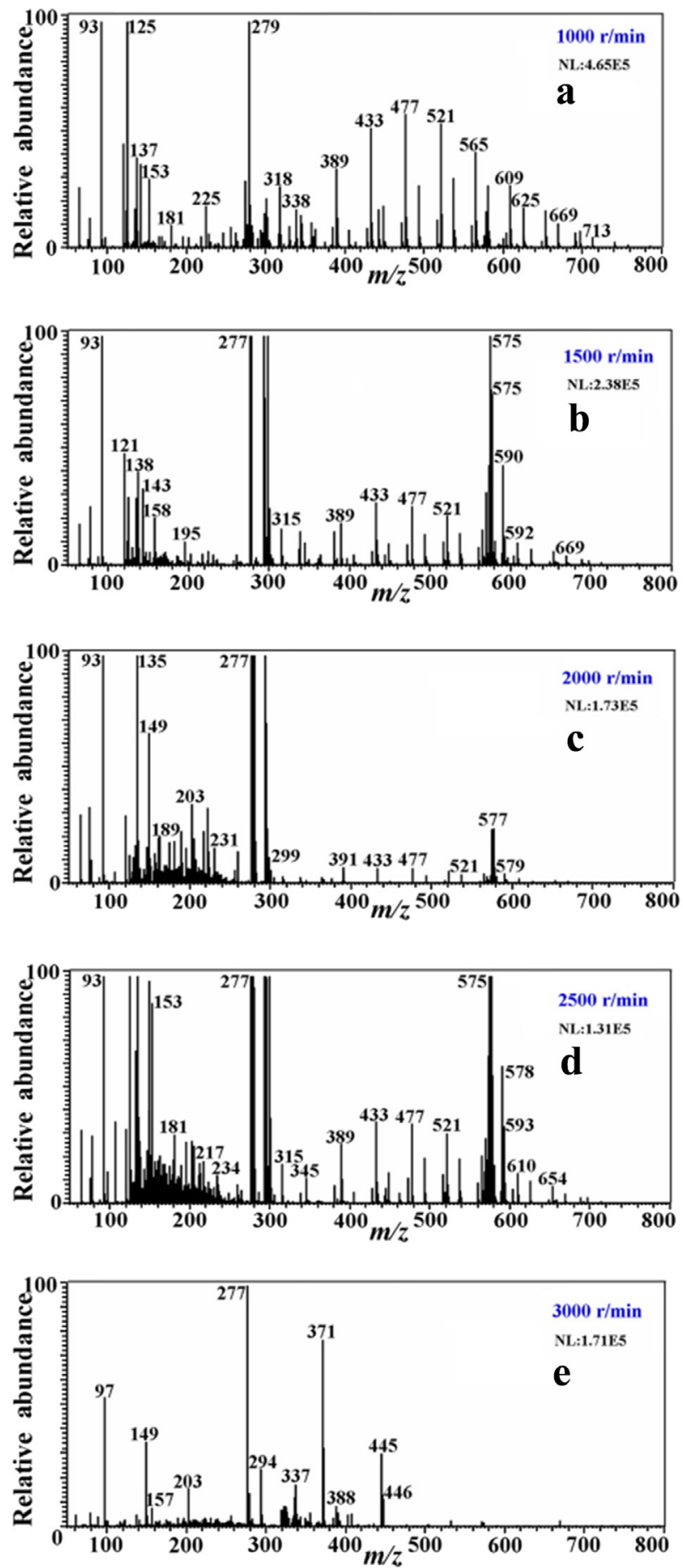

Fig. 4 - EAPCI-MS spectra of PMs with a size of $0.45-1.00 \mu \mathrm{m}$ collected under different automobile engine combustion conditions. Engine speeds at (a) 1000, (b) 1500, (c) 2000, (d) 2500 and (e) $3000 \mathrm{r} / \mathrm{min}$. Note: the relative abundance of $\mathrm{m} / \mathrm{z}$ 120-800 was magnified 30 times.

at the engine speed of $1000 \mathrm{r} / \mathrm{min}$. The results demonstrated that the fine PMs were likely produced by the engine at low speeds, indicating that low air intake at low speeds resulted in incomplete combustion of the fuel inside the automobile engine.

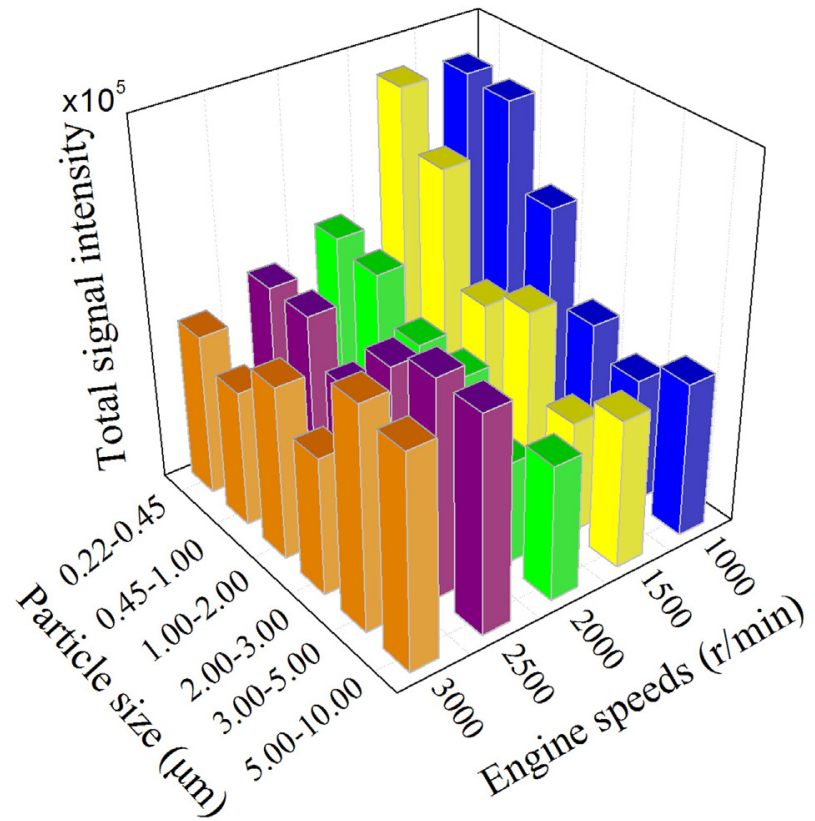

Fig. 5 - Analysis of automobile exhaust PMs from different combustion conditions using EAPCI-MS.

\subsection{EAPCI-MS analysis of PMs generated at different combustion conditions}

The different combustion conditions inside the automobile engine have a significant impact on the chemical composition of the exhaust PMs. For a demonstration, the exhaust PMs of $1.00-2.00 \mu \mathrm{m}$ generated at different engine combustion conditions with various speeds of 1000, 1500, 2000, 2500, and $3000 \mathrm{r} / \mathrm{min}$ were studied by EAPCI-MS, as shown in Fig. 4. The organic chemical compounds provided similar spectral fingerprints for the PM samples with the same sizes $(1.00-2.00 \mu \mathrm{m})$ collected from different engine conditions, but the total signal intensity of all organic compounds observed in the spectra were surprisingly differentiated from each other. The intensities of the major mass peaks gradually changed while increasing the speed of the automobile, e.g. the mass peaks of $\mathrm{m} / \mathrm{z}$ at $93,279,433,477$ and 575 continually declined with increasing engine speed. New ions were detected at high engine speed, such as the ions of $\mathrm{m} / \mathrm{z}$ at 371 detected at engine speed of $3000 \mathrm{r} / \mathrm{min}$. These results might all be attributed to the difference in combustion efficiency at various engine speeds. Moreover, higher signal intensities were observed at engine speeds of 1000 and $1500 \mathrm{r} / \mathrm{min}$, and the quantity of the total organic compounds decreased when the engine speed was increased from 1000 to $2500 \mathrm{r} / \mathrm{min}$. However, once the engine speed exceeded $2500 \mathrm{r} / \mathrm{min}$, the quantity of total organic compounds increased with increasing engine speed from 2500 to $3000 \mathrm{r} / \mathrm{min}$. These data showed that the efficiency of gasoline combustion changed at different engine speeds, and a higher combustion efficiency was obtained when the engine speed reached $2500 \mathrm{r} / \mathrm{min}$. These results further indicated that traffic congestion would produce more fine PMs and air pollutants than a smooth flow of traffic. Therefore, avoiding and relieving traffic congestion should be effective methods for reduction of the air pollution from vehicles. 
The relationship between the total organic compound levels of PMs with different sizes and the automobile combustion conditions was further explored using EAPCI-MS. As shown in Fig. 5, the total organic compound levels recorded from PMs of 0.22-1.00 $\mu \mathrm{m}$ were much higher than the rest of the samples tested at engine speeds from 1000 to $3000 \mathrm{r} / \mathrm{min}$. Interestingly, the sizes of PMs were substantially increased along with the rise of engine speed. For example, the major fraction of PMs collected at engine speeds of $1000 \mathrm{r} / \mathrm{min}$ was in the size range $0.45-1.00 \mu \mathrm{m}$, while PMs of $5.00-10.00 \mu \mathrm{m}$ became the major fraction at higher engine speeds of $3000 \mathrm{r} / \mathrm{min}$. With increased engine speed, more gas-phase $\mathrm{H}_{2} \mathrm{O}$ was produced in the combustion cylinder due to the high combustion efficiency. The water vapor quickly cooled down and collided with the fine PMs, which might become glued to each other by water molecules, resulting in the formation of PMs with large sizes during the exhaust gas emission process. Therefore, fine PMs could be easily formed at low engine speeds (1000 and $1500 \mathrm{r} / \mathrm{min}$ ), and larger, heavier PMs could be produced at high engine speeds (3000 r/min). The degree of completion of fuel combustion inside an automobile engine, however, can be adjusted by tuning the quantity of air intake and gasoline discharge.

\section{Conclusions}

Automobile exhaust PMs contribute to a significant fraction of the global PMs. To explore the potential chemical component dependence of the PMs on the engine combustion conditions, a novel method based on EAPCI-MS was developed to facilitate the recording of the molecular profiles of PMs collected from the exhaust gas generated at different vehicle engine speeds. By comparatively studying organic components embedded in differentially sized PMs (e.g., 0.22-0.45, 0.45-1.00, 1.00-2.00, 2.00-3.00, 3.00-5.00, and 5.00-10.00 $\mu \mathrm{m}$ ) generated at different engine speeds (e.g., 1000, 1500, 2000, 2500, and $3000 \mathrm{r} / \mathrm{min}$ ), the dependence of the chemical composition of PMs on the engine speed (i.e., the combustion conditions) of an automobile has been revealed at the molecular level. Organic chemicals, including alcohols, aldehydes, and esters, were detected from all the PMs tested, with varied concentration levels for each individual PM sample. The experimental data showed that the EAPCI-MS, by enabling molecular characterization of exhausted PMs in exhaust, is a promising analytical tool for advanced studies on PMs and their dependence on fuel combustion inside the engines of vehicles.

\section{Acknowledgements}

The work was supported by the National Natural Science Foundation of China (Nos. 21675021, 21607161, 21520102007), the Program for Changjiang Scholars and Innovative Research Team in Universities (PCSIRT) (No. IRT 13054), the Science and Technology Planning Project at the Ministry of Science and Technology of Jiangxi Province, China (No. 20152ACH80010), and Jiangxi Key Laboratory for Mass Spectrometry and Instrumentation Open Foundation (No. JXMS201501, JXMS201516).

\section{R E F E R E N C E S}

Bruggemann, M., Karu, E., Stelzer, T., Hoffmann, T., 2015. Real-time analysis of ambient organic aerosols using aerosol flowing atmospheric-pressure afterglow mass spectrometry (AeroFAPA-MS). Environ. Sci. Technol. 49 (9), 5571-5578.

Calvo, A.I., Alves, C., Castro, A., Pont, V., Vicente, A.M., Fraile, R., 2013. Research on aerosol sources and chemical composition: past, current and emerging issues. Atmos. Res. 120-121, 1-28.

Chen, Y., Tian, G., Zhou, M., Huang, Z., Lu, C., Hu, P., Gao, J., Zhang, Z., Tang, X., 2016a. Catalytic control of typical particulate matters and volatile organic compounds emissions from simulated biomass burning. Environ. Sci. Technol. 50 (11), 5825-5831.

Chen, Y., Schleicher, N., Cen, K., Liu, X., Yu, Y., Zibat, V., Dietze, V., Fricker, M., Kaminski, U., Chen, Y., Chai, F., Norra, S., 2016b. Evaluation of impact factors on $\mathrm{PM}_{2.5}$ based on long-term chemical components analyses in the megacity Beijing, China. Chemosphere 155, 234-242.

Chen, Y., Schleicher, N., Fricker, M., Cen, K., Liu, X.L., Kaminski, U., Yu, Y., Wu, X.F., Norra, S., 2016c. Long-term variation of black carbon and $\mathrm{PM}_{2.5}$ in Beijing, China with respect to meteorological conditions and governmental measures. Environ. Pollut. 212, 269-278.

Choi, J.-K., Heo, J.-B., Ban, S.-J., Yi, S.-M., Zoh, K.-D., 2012. Chemical characteristics of $\mathrm{PM}_{2.5}$ aerosol in Incheon, Korea. Atmos. Environ. 60, 583-592.

Daellenbach, K.R., Bozzetti, C., Křepelová, A., Canonaco, F., Wolf, R., Zotter, P., Fermo, P., Crippa, M., Slowik, J.G., Sosedova, Y., Zhang, Y., Huang, R.J., Poulain, L., Szidat, S., Baltensperger, U., El Haddad, I., Prévôt, A.S.H., 2016. Characterization and source apportionment of organic aerosol using offline aerosol mass spectrometry. Atmos. Meas. Tech. 9 (1), 23-39.

Dunmore, R.E., Hopkins, J.R., Lidster, R.T., Lee, J.D., Evans, M.J., Rickard, A.R., Lewis, A.C., Hamilton, J.F., 2015. Diesel-related hydrocarbons can dominate gas phase reactive carbon in megacities. Atmos. Chem. Phys. 15 (17), 9983-9996.

Ensberg, J.J., Hayes, P.L., Jimenez, J.L., Gilman, J.B., Kuster, W.C., de Gouw, J.A., Holloway, J.S., Gordon, T.D., Jathar, S., Robinson, A.L., Seinfeld, J.H., 2014. Emission factor ratios, SOA mass yields, and the impact of vehicular emissions on SOA formation. Atmos. Chem. Phys. 14 (5), 2383-2397.

Gerald, L.Z., Berg, D.R., Vasys, V.N., Dettmann, M.E., Zielinska, B., Schauer, J.J., 2010. Analysis of C1, C2, and C10 through C33 particle-phase and semi-volatile organic compound emissions from heavy-duty diesel engines. Atmos. Environ. 44 (8), 1108-1115.

Goel, R., Guttikunda, S.K., 2015. Evolution of on-road vehicle exhaust emissions in Delhi. Atmos. Environ. 105, 78-90.

Hoffmann, T., Huang, R.J., Kalberer, M., 2011. Atmospheric analytical chemistry. Anal. Chem. 83 (12), 4649-4664.

Hu, B., Li, J., Yang, S., Liang, H., Chen, H., 2008. Extractive atmospheric pressure chemical ionization. J. Chin. Mass Spectrom. Soc. 29 (5), 119-120.

Kaivosoja, T., Jalava, P.I., Lamberg, H., Virén, A., Tapanainen, M., Torvela, T., Tapper, U., Sippula, O., Tissari, J., Hillamo, R., Hirvonen, M.R., Jokiniemi, J., 2013. Comparison of emissions and toxicological properties of fine particles from wood and oil boilers in small (20-25 kW) and medium (5-10 MW) scale. Atmos. Environ. 77, 193-201.

Karar, K., Gupta, A.K., 2007. Source apportionment of PM10 at residential and industrial sites of an urban region of Kolkata, India. Atmos. Res. 84 (1), 30-41.

Kinsey, J.S., Hays, M.D., Dong, Y., Williams, D.C., Logan, R., 2011. Chemical characterization of the fine particle emissions from commercial aircraft engines during the aircraft particle emissions eXperiment (APEX) 1 to 3. Environ. Sci. Technol. 45 (8), 3415-3421. 
Kleeman, M.J., Schauer, J.J., Cass, G.R., 2000. Size and composition distribution of fine particulate matter emitted from motor vehicles. Environ. Sci. Technol. 34 (7), 1132-1142.

Kong, Y., Lin, L., Zhang, Y., Lu, F., Xie, K., Liu, R., Guo, L., Shao, S., Yang, J., Shi, D., 2008. Studies on polyethylene glycol/polyethersulfone composite membranes for FCC gasoline desulphurization by pervaporation. Eur. Polym. J. 44 (10), 3335-3343.

Kundu, S., Fisseha, R., Putman, A.L., Rahn, T.A., Mazzoleni, L.R., 2012. High molecular weight SOA formation during limonene ozonolysis: insights from ultrahigh-resolution FT-ICR mass spectrometry characterization. Atmos. Chem. Phys. 12 (12), 5523-5536.

Kuwayama, T., Collier, S., Forestieri, S., Brady, J.M., Bertram, T.H., Cappa, C.D., Zhang, Q., Kleeman, M.J., 2015. Volatility of primary organic aerosol emitted from light duty gasoline vehicles. Environ. Sci. Technol. 49 (3), 1569-1577.

Li, Q., Jiang, J., Zhang, Q., Zhou, W., Cai, S., Duan, L., Ge, S., Hao, J., 2016. Influences of coal size, volatile matter content, and additive on primary particulate matter emissions from household stove combustion. Fuel 182, 780-787.

Liu, B., Song, N., Dai, Q., Mei, R., Sui, B., Bi, X., Feng, Y., 2016a. Chemical composition and source apportionment of ambient $\mathrm{PM}_{2.5}$ during the non-heating period in Taian, China. Atmos. Res. 170, 23-33.

Liu, J., Li, J., Li, W., 2016b. Temporal patterns in fine particulate matter time series in Beijing: a calendar view. Sci Rep 6, 32221-32226.

Maria, S.F., Russell, L.M., Turpin, B.J., Porcja, R.J., 2002. FTIR measurements of functional groups and organic mass in aerosol samples over the Caribbean. Atmos. Environ. 36 (33), 5185-5196.

Mortaheb, H.R., Ghaemmaghami, F., Mokhtarani, B., 2012. A review on removal of sulfur components from gasoline by pervaporation. Chem. Eng. Res. Des. 90 (3), 409-432.

Nguyen, H.T., Kim, K.-H., Park, C., 2015. Long-term trend of $\mathrm{NO}_{2}$ in major urban areas of Korea and possible consequences for health. Atmos. Environ. 106, 347-357.

Parshintsev, J., Hyötyläinen, T., 2015. Methods for characterization of organic compounds in atmospheric aerosol particles. Anal. Bioanal. Chem. 407 (20), 5877-5897.

Peck, J., Gonzalez, L.A., Williams, L.R., Xu, W., Croteau, P.L., Timko, M.T., Jayne, J.T., Worsnop, D.R., Miake-Lye, R.C., Smith, K.A., 2016. Development of an aerosol mass spectrometer lens system for $\mathrm{PM}_{2.5}$. Aerosol Sci. Technol. 50 (8), 781-789.

Police, S., Sahu, S.K., Pandit, G.G., 2016. Chemical characterization of atmospheric particulate matter and their source apportionment at an emerging industrial coastal city, Visakhapatnam, India. Atmos. Pollut. Res. 7 (4), 725-733.

Pope, C.A., Dockery, D.W., 2006. Health effects of fine particulate air pollution: lines that connect. J. Air Waste Manage. Assoc. 56 (6), 709-742.

Poschl, U., Shiraiwa, M., 2015. Multiphase chemistry at the atmosphere-biosphere interface influencing climate and public health in the anthropocene. Chem. Rev. 115 (10), 4440-4475.

Pui, D.Y.H., Chen, S.-C., Zuo, Z., 2014. PM2.5 in China: measurements, sources, visibility and health effects, and mitigation. Particuology $13(2), 1-26$.
Qu, L., Wang, Z., Zhang, J., 2016. Influence of waste cooking oil biodiesel on oxidation reactivity and nanostructure of particulate matter from diesel engine. Fuel 181, 389-395.

Roach, P.J., Laskin, J., Laskin, A., 2010. Molecular characterization of organic aerosols using nanospray-desorption/electrospray ionization-mass spectrometry. Anal. Chem. 82 (19), 7979-7986.

Romonosky, D.E., Laskin, A., Laskin, J., Nizkorodov, S.A., 2015. High-resolution mass spectrometry and molecular characterization of aqueous photochemistry products of common types of secondary organic aerosols. J. Phys. Chem. A 119 (11), 2594-2606.

Ruger, C.P., Sklorz, M., Schwemer, T., Zimmermann, R., 2015. Characterisation of ship diesel primary particulate matter at the molecular level by means of ultra-high-resolution mass spectrometry coupled to laser desorption ionisation-comparison of feed fuel, filter extracts and direct particle measurements. Anal. Bioanal. Chem. 407 (20), 5923-5937.

Sippula, O., Stengel, B., Sklorz, M., Streibel, T., Rabe, R., Orasche, J., Lintelmann, J., Michalke, B., Abbaszade, G., Radischat, C., Gröger, T., Schnelle-Kreis, J., Harndorf, H., Zimmermann, R., 2014. Particle emissions from a marine engine: chemical composition and aromatic emission profiles under various operating conditions. Environ. Sci. Technol. 48 (19), 11721-11729.

Spracklen, D.V., Jimenez, J.L., Carslaw, K.S., Worsnop, D.R., Evans, M.J., Mann, G.W., Zhang, Q., Canagaratna, M.R., Allan, J., Coe, H., McFiggans, G., Rap, A., Forster, P., 2011. Aerosol mass spectrometer constraint on the global secondary organic aerosol budget. Atmos. Chem. Phys. 11 (23), 12109-12136.

Tao, S., Lu, X., Levac, N., Bateman, A.P., Nguyen, T.B., Bones, D.L., Nizkorodov, S.A., Laskin, J., Laskin, A., Yang, X., 2014. Molecular characterization of organosulfates in organic aerosols from Shanghai and Los Angeles urban areas by nanospray-desorption electrospray ionization high-resolution mass spectrometry. Environ. Sci. Technol. 48 (18), 10993-11001.

Tu, P., Hall, W.A., Johnston, M.V., 2016. Characterization of highly oxidized molecules in fresh and aged biogenic secondary organic aerosol. Anal. Chem. 88 (8), 4495-4501.

Yadav, S., Tandon, A., Attri, A.K., 2013. Characterization of aerosol associated non-polar organic compounds using TD-GC-MS: a four year study from Delhi, India. J. Hazard. Mater. 252-253 (10), 29-44.

Yuan, Y., Liu, S., Castro, R., Pan, X., 2012. PM2.5 monitoring and mitigation in the cities of China. Environ. Sci. Technol. 46 (7), 3627-3628.

Zhou, M., Qiao, L., Zhu, S., Li, L., Lou, S., Wang, H., Wang, Q., Tao, S., Huang, C., Chen, C., 2016a. Chemical characteristics of fine particles and their impact on visibility impairment in Shanghai based on a 1-year period observation. J. Environ. Sci. 7 (4), 725-733.

Zhou, Y., Huang, X.H.H., Griffith, S.M., Li, M., Li, L., Zhou, Z., Wu, C., Meng, J., Chan, C.K., Louie, P.K.K., Yu, J.Z., 2016b. A field measurement based scaling approach for quantification of major ions, organic carbon, and elemental carbon using a single particle aerosol mass spectrometer. Atmos. Environ. $143,300-312$ 